\title{
Dermatitis atópica
}

I. Querol Nasarre

Profesor Titular de Dermatología. Facultad de Medicina. Universidad de Zaragoza. Zaragoza. España.

Rev Pediatr Aten Primaria. 2009; I (Supl I7):s3 17-s329

Ignacio Querol Nasarre, iqueroln@unizar.es

\section{Resumen}

La dermatitis atópica (DA) es una dermatosis inflamatoria de curso crónico caracterizada por un intenso prurito. Se trata de una enfermedad multifactorial que resultaría de la interacción de factores genéticos, ambientales, defectos en la función barrera y una serie de factores inmunológicos. La DA afecta sobre todo a la infancia, pero también puede persistir o comenzar en el adulto. Caracterizada por un intenso prurito, morfología y distribución típica de sus lesiones, se ha convertido en la atracción de dermatólogos pediatras, pediatras, alergólogos e inmunólogos. Su prevalencia está aumentando y dos hechos son relevantes en la actualidad: el gran impacto en la calidad de vida de los pequeños pacientes y sus familias y la demostración, que es la primera manifestación del síndrome atópico. Las lesiones clínicas de la DA afectan típicamente a las flexuras, en forma de eczema exudativo o liquenificado; existe un número no despreciable de pacientes con lesiones de distribución o morfología atípica. Revisamos la etiopatogenia, criterios diagnósticos, clínica, diagnóstico diferencial y tratamiento, incidiendo en la terapéutica de la DA severa o refractaria a los tratamientos convencionales, haciendo especial hincapié en los recientes avances en el conocimiento de su fisiopatología, así como su manejo a través de algoritmos terapéuticos.

Palabras claves: Dermatitis atópica, Genética, Inmunología, Corticoides, Inmunomoduladores.

\section{Abstract}

Atopic dermatitis $(A D)$ is the expression of a chronic inflammatory cutaneous disease that generally begins in the early childhood.

Characterised by an intense pruritus and the morphology and distribution of its injuries, it is currently a field of interest for paediatric dermatologists, paediatricians, allergists and immunologists. Its prevalence is increasing and two facts are relevant at present: the adverse effect on the quality of life of the patients and the proof that is the first sign of the atopic syndrome.

The controversies in the treatment guidelines are displacing the great advances in pathophysiology, as well as the managing of $A D$ with algorithms is displacing the art of medical treatment.

Key words: Atopic dermatitis, Genetics, Immunology, Steroids, Immunomodulators.

El autor declara no presentar posibles conflictos de intereses en relación con la preparación y publicación de este artículo. 


\section{Definición}

La dermatitis atópica (DA) es un proceso inflamatorio cutáneo crónico, intensamente pruriginoso, de carácter recurrente. Usualmente aparece durante la infancia temprana y la niñez, pero puede persistir o comenzar en la vida adulta.

\section{Epidemiología}

La prevalencia de la DA varía de unas zonas geográficas a otras $y$, en general, es mayor cuanto más al norte se sitúa el área estudiada y cuanto más alto es su nivel de desarrollo industrial parece ir aumentando, por lo que no hay un entendimiento claro de los factores determinantes del incremento. En algunas poblaciones se han encontrado manifestaciones de DA en la edad infantil entre un $5-10 \%$, sin diferencias significativas en relación con el sexo.

Las estadísticas revelan una prevalencia infantil global de entre el $10-20 \%$ y en los adultos del $1-3 \%$.

\section{Etiopatogenia}

Aunque la causa final sigue siendo desconocida, se han identificado múltiples factores.

\section{Factores genéticos}

Entre un $70-80 \%$ de los pacientes tienen una historia familiar positiva de ato- pia. La influencia genética es compleja, siendo el componente materno el más importante. Un estudio reciente a gran escala de análisis de microarreglos de ADN ha demostrado que cuatro genes involucrados en la diferenciación epidérmica, ubicados en el cromosoma 1q21, muestran diferentes niveles de expresión en lesiones eczematosas de la piel en comparación con controles.

Caracterizar el patrón genético de la DA constituye en sí mismo un desafío, teniendo en cuenta los diferentes fenotipos y las heterogeneidades genética e inmunológica. Se sabe que tiene una elevada incidencia familiar, aunque la concordancia no es total; en gemelos univitelinos la tasa de concordancia llega al 77, y al 15\% en los dicigóticos.

En el estudio del genoma, hasta el momento han existido dos aproximaciones diferentes; la primera, que podríamos llamar de "ligamiento", trata de buscar una relación entre determinado fenotipo y una región cromosómica; la segunda, que podríamos llamar de "asociación", se centra en un determinado cromosoma y un locus genético, y trata de asociar los polimorfismos de ese gen con la expresión clínica de la DA.

Sobre la DA se han realizado dos estudios extensos de ligamiento genético, observándose en uno de ellos un liga- 
miento con el locus $3 q 21$, mientras que el otro muestra ligamiento a 1q21, $17 q 25,20 p, 16 q$ y $5 q 31$. Estos locus no habían sido asociados a asma u otras manifestaciones de atopia, mientras que sí se habían relacionado con psoriasis, lo cual conduce a pensar que la atopia es un fenómeno secundario a la DA y que estas regiones contienen genes relacionados con la inmunidad e inflamación cutáneas. Algunas investigaciones se han centrado en el cromosoma 5q31-33, puesto que aquí se agrupan una serie de genes relacionados con la producción de citoquinas de estirpe Th2 (IL-13, II-4, IL-5). Se ha encontrado una asociación entre la DA y una actividad aumentada del gen que promueve la síntesis de IL-4 y de IL-13, lo que sugiere un aumento de la respuesta alérgica en pacientes con DA. Otra asociación relaciona la DA con genes que ejercen un efecto sobre la síntesis de IgE, asociados al locus 11q13. Por otra parte, hay evidencias de un defecto en un gen denominado SPINK5, situado en el cromosoma 5q31, este codifica la síntesis de una proteína denominada LEKTI, la cual tiene una actividad inhibidora de las proteasas que utilizan algunas bacterias (Staphylococcus aureus) o algunos alérgenos (Dermatofagoides pteronissynus) para producir lesiones inflamato- rias en la barrera cutánea, haciendo así a estos pacientes más susceptibles al ataque de aquellos.

Respecto al consejo genético e implementación de medidas de prevención primaria debe estar basada en el hecho de que, cuando ambos padres presentan enfermedad atópica de un determinado tipo, el riesgo de cada hijo de presentar un fenotipo similar es del $70 \%$, mientras que si ambos padres tienen enfermedades atópicas diferentes, el riesgo es del $30 \%$.

\section{Factores inmunológicos}

Los atópicos presentan una respuesta inmunitaria humoral y celular alterada, que facilita la reacción con antígenos ambientales.

Las alteraciones evidenciadas más clásicamente son las siguientes: aumento de la IgE sérica, alteración de las subpoblaciones linfocitarias, alteración de las inmunoglobulinas y aumento de la expresión en la membrana de las células de Langerhans.

$\mathrm{Ha}$ existido un considerable debate sobre el patrón inmunológico y la expresión de citoquinas en la DA, y ello es debido a que los hallazgos dependen del tiempo de evolución de la muestra biopsiada. En los pacientes atópicos existe una predisposición a mantener respuestas Th2, con de- 
sarrollo de respuestas frente a antígenos inadecuados, como alérgenos ambientales, superantígenos bacterianos y autoantígenos epidérmicos. Presentan un defecto específico cutáneo de las respuestas inmunes (respuestas defectuosas de inmunidad celular retardada, defectos en la respuesta de linfocitos $T$ citotóxicos, etc.) no asociado a inmunosupresión sistémica. Las células de Langerhans también presentan un incremento en su número y actividad como células presentadoras de antígeno en las zonas de piel afecta, activando las células $T y$ liberando IgE.

El comienzo de la DA está asociado con la producción de citoquinas Th2 (IL4 e IL-13) implicadas en la fase aguda de la inflamación tisular, mientras que la IL5, involucrada en el desarrollo y supervivencia de los eosinófilos predomina en la forma crónica, así como GM-CSF, IL-12, IL-18, IL-11 y TGF-B1. La expresión aumentada de quimocinas (eotaxina, RANTES) contribuye a la infiltración de macrófagos, eosinófilos y células $T$ en las lesiones agudas y crónicas de DA.

\section{Factores constitucionales}

Alteraciones de la reactividad vascular y farmacológica.

Los vasos muestran una marcada tendencia a la vasoconstricción (dermografismo blanco y palidez centrofacial).
- Alteraciones de la fisiología de la piel.

- Disminución del umbral del prurito.

- Alteración en la eliminación de la sudoración.

- Alteración del manto lipídico de la piel.

- Personalidad atópica: son niños vivos, inteligentes, simpáticos, hiperactivos, con labilidad emocional y tendencia a la depresión. Defensivos, obsesivos y agresivos. En estas personas hay ansiedad, hostilidad, timidez, falta de adaptación y rechazo a la madre.

\section{Factores exógenos o desencadenantes}

Como factores desencadenantes de la DA se han involucrado:

1. Estrés, al inducir cambios inmunológicos.

2. Alérgenos, tanto alimentarios (huevo, leche, trigo, soja, cacahuete), como aeroalérgenos (ácaros del polvo, malezas, epitelios de animales, hongos).

3. Irritantes tipo limpiadores cutáneos, ropa de lana o fibras sintéticas, agua caliente, jabones, detergentes.

4. Clima con temperaturas extremas, humedad o sequedad excesiva.

5. Microorganismos, especialmente $S$. aureus, que es un colonizador habitual de la piel de los atópicos y exacerba la 
DA por medio de la secreción de toxinas llamadas superantígenos, que activan a las células $T$, preferentemente $T h 2, y$ a los macrófagos y, además, inducen corticorresistencia; el rascado facilita la acción de estas bacterias al debilitar la barrera cutánea. Se ha relacionado la presencia de Malassezzia furfur y DA, con afectación preferente del polo cefálico, en adultos jóvenes. El proceso estaría ligado a la producción de autoantígenos, dado que la enzima MnSOD humana puede actuar como autoalérgeno, con reactividad cruzada con la enzima fúngica.

\section{Manifestaciones clínicas}

Clásicamente se distinguen la DA típica y las manifestaciones atípicas.

\section{DA típica}

Se divide en tres etapas: la del lactante, la infantil y la del adolescente-adulto. Lo más frecuente es que debute en el lactante. Puede haber casos de debut tardío en la infancia e incluso en el adulto. Clínicamente, las fases de la enfermedad se diferencian por su localización y por el aspecto de las lesiones.

\section{DA del lactante}

Suele debutar entre el tercer y el quinto mes de vida en el $75 \%$ de los casos.
En cara a nivel de mejillas y mentón, se observan placas eritematoedematosas, vesiculosas, exudativas, simétricas, que característicamente respetan el triángulo nasolabial. Son frecuentes las costras melicéricas por sobreinfección. También se pueden afectar las superficies de extensión de las extremidades.

La enfermedad se va a cursar en brotes, de intensidad y duración variables, hasta la edad de 2 años, en la que cura o se perpetúa.

\section{DA infantil-escolar}

Las zonas afectadas son los pliegues flexurales, nuca, dorso de pies y manos. Las lesiones evolucionan del aspecto exudativo del lactante a un aspecto de liquenificación. Se observa eritema mal delimitado, pápulas lesiones por rascado y liquenificación.

\section{DA del adolescente y del adulto}

Se fija su inicio al final de la fase infantil a partir de los 10 años o en la pubertad. Sus áreas de predilección son: cara (frente, párpados, región perioral), cuello (especialmente nuca), parte alta del tórax y hombros, grandes pliegues flexurales y dorso de las manos. Las lesiones características son las placas de liquenificación. Pueden aparecer también eczema de manos, dishidrosis y prurigo nodular. La 
mayor parte de los pacientes evolucionan hacia la resolución antes de los 20 años, siendo muy infrecuentes las manifestaciones de la enfermedad después de los 30 años.

\section{Formas atípicas}

- Pitiriasis alba: constituida por una lesión macular blanquecina, levemente descamativa, de forma usualmente redondeada y que cursa sin molestias subjetivas. Predomina en cara y raíces de los miembros. Suele ser frecuente su confusión con la pitiriasis versicolor, una micosis superficial causada por el $P$. orbiculare. Esta enfermedad es rara en niños, no suele afectar a la cara y predomina en tronco.

- Eczema dishidrótico: las lesiones se localizan en los laterales de los dedos y en el arco plantar de los pies. Consisten en eritema, pápulas y vesículas que al romperse dan lugar a erosiones y en fases avanzadas produce liquenificación, descamación grietas y fisuras.

- Dermatitis plantar juvenil: las lesiones suelen limitarse a la cara plantar de los dedos de los pies y al tercio distal de las plantas. La piel está eritematosa, brillante y con tendencia a la descamación blanquecina. El diagnóstico diferencial debe hacerse con la forma queratósica de la tiña pedís y con el eczema de contacto.

- Prurigo: aparecen de forma difusa pápulas y nódulos, que son excoriados por el rascado y evolucionan a cicatrices y costras. En el diagnóstico diferencial se consideran: sarna, reacciones por picaduras, el prurigo secundario a fármacos y a trastornos sistémicos.

- Queilitis: se manifiesta como sequedad, descamación, fisuras y grietas.

- Prurito anogenital: en los atópicos es frecuente el prurito anal, genital o anogenital de carácter crónico.

- Eczema areolar: en mujeres atópicas son frecuentes las lesiones eczematosas en pezón y areola, favorecidas por el roce con prendas sintéticas.

- Eczema del conducto auditivo externo.

- Eczema numular: cursa con lesiones redondeadas, eczematosas, del tamaño aproximado de una moneda y localizadas preferentemente en caras de extensión de las extremi- 
dades. Se deben tener en cuenta en su diagnóstico diferencial: las dermatofitosis, la psoriasis y la pitiriasis rosada de Gibert.

- Xerosis: es muy frecuente la presencia de una piel seca y con fina descamación. Esta sequedad cutánea es debida a la pérdida o disminución del componente lipidito de la piel.

- Queratosis folicular: son micropápulas queratósicas centradas por folículos que predominan en caras laterales de brazos y muslos.

\section{Complicaciones}

Las más frecuentes son las sobreinfecciones (impétigo secundario), la dermatitis por contacto y el corticoestropeo que produce DA eritrodérmicas de muy difícil manejo.

Las infecciones virales que se presentan en pacientes atópicos incluyen al herpes simple, la vaccinia, las verrugas vulgares $y$ el molusco contagioso, principalmente. La infección viral más frecuente es el herpes simple, el cual puede extenderse localmente o diseminarse, produciendo la erupción variceliforme de Kaposi, que in-

Tabla I. Criterios de Hanifin y Rajka para el diagnóstico de DA

\section{Criterios mayores}

- Prurito.

- Morfología y distribución característica:

- Liquenificación en flexuras en adultos.

- Afectación de cara, flexuras y superficies de extensión en niños y jóvenes.

- Combinación de estos patrones en niños y adultos.

- Carácter crónico y recidivante.

- Historia personal o familiar de atopia.

Criterios menores

- Xerosis.

- Ictiosis/exageración pliegues palmares/ queratosis pilar.

- Reactividad cutánea inmediata (tipo I) a los test cutáneos.

- Elevación de valores séricos de IgE.

- Edad precoz de comienzo.

- Tendencia a infecciones cutáneas y déficit de la inmunidad celular.

- Tendencia a dermatitis inespecíficas de pies y manos.
- Eczema de pezón.

- Queilitis.

- Conjuntivitis recidivante.

- Pliegue infraorbitario de Dennie-Morgan.

- Queratocono.

- Catarata subcapsular anterior.

- Ojeras u oscurecimiento periocular.

- Palidez facial o eritema en cara.

- Pitiriasis alba.

- Pliegues en parte anterior de cuello.

- Prurito provocado por la sudoración.

- Intolerancia a la lana y los solventes de las grasas.

- Acentuación perifolicular.

- Intolerancia a algunos alimentos.

- Evolución influenciada por factores ambientales y emocionales.

- Dermografismo blanco.

Han de cumplirse tres o más criterios mayores y tres o más criterios menores. 
cluso puede llevar a la muerte al paciente si no es tratada oportunamente con aciclovir.

Las infecciones por hongos son tres veces más frecuentes en pacientes atópicos que en la población general, sobre todo por dermatofitos (T. rubrum).

\section{Diagnóstico}

Las manifestaciones clínicas son la base del diagnóstico, ya que ni la histología ni ninguna otra prueba de laboratorio son específicas de la enfermedad. El diagnóstico puede verse dificultado si la DA debuta en la infancia o en el adulto con alguna de las formas atípicas. Los antecedentes familiares y personales de atopia pueden sernos de ayuda.

Al no existir criterios bioquímicos que establezcan de forma fehaciente el diagnóstico de certeza se debe recurrir al manejo de criterios clínicos. Los criterios universalmente más aceptados son los establecidos en 1983 por Hanifin y Rajka (tabla I).

La determinación de la IgE suele mostrar un nivel aumentado, pero hay que tener en cuenta que un $20 \%$ de los atópicos pueden mostrar determinaciones normales $\mathrm{y}$, al revés, otras patologías e incluso individuos sanos pueden mostrar una elevación de lgE.
Un 20\% de los pacientes tiene alergia a algún alimento demostrada por RAST.

Tratamiento

El manejo es multidisciplinario e incluye explicar con detalle a la familia del niño qué es la DA, qué pronóstico tiene y cuáles son los objetivos del tratamiento. Es muy importante aclarar que la DA no es una alergia a ninguna sustancia determinada y que en ningún modo va a resolverse por realizar "pruebas alérgicas" ni por eliminar alimentos.

Más que pensar en una posible monoterapia, tendremos que combinar una amplia gama de recursos que incluyen:

\section{Medidas generales para evitar} factores desencadenantes

- Exceso de lavado, uso de jabones detergentes.

- Evitar desencadenantes específicos, como aeroalérgenos y alimentos (alimentos solo en un 20\%).

- Ropas ajustadas, excesivas y fibras sintéticas.

- Irritantes primarios: polvo, grasas, disolventes, barnices, etc.

- Trabajos inadecuados: carpintería, minería, mecánica, peluquería, etc.

- Climas con temperaturas extremas. 
- Estrés emocional y conflictos familiares.

- Infecciones intercurrentes, bacterianas, víricas o fúngicas.

\section{Cuidado de la piel: hidratación}

Es la base del tratamiento de mantenimiento y juega un papel importante en el brote agudo de la enfermedad, ya que permite disminuir la cantidad de esteroides tópicos requeridos para el control de la inflamación.

No deben usarse jabones alcalinos. Se utilizan jabones de pH ácido, aceites de baño y los baños de avena coloidal, con carácter emoliente. Tras el baño y dentro de los tres minutos se aplicarán hidratantes y emolientes que permitan retener el agua manteniendo la barrera suave y flexible. El uso de esponjas, talcos, perfumes, lociones y el secado por fricción deberán estar proscritos.

\section{Tratamiento del prurito}

Los antihistamínicos anti $\mathrm{H}-1$ clásicos o sedativos son los más empleados. Si bien su utilidad es relativa como antipruriginosos, su efecto sedante condiciona un alivio de la sintomatología. En casos rebeldes se usa la asociación de anti $\mathrm{H} 1$ con anti H2. No deben utilizarse antihistamínicos tópicos por su carácter sensibilizante.

\section{Reducir la inflamación con glucocorticoides o inhibidores de la calcineurina tópicos}

\section{Corticoides tópicos}

La DA de grado leve es muy frecuente y es de manejo usual en la práctica de atención primaria. El eje de tratamiento continúa siendo el uso de emolientes y de corticoesteroides tópicos (tabla II).

Existe buena evidencia en apoyo de la eficacia de los esteroides tópicos que solamente requieren aplicación una vez al día. Sin embargo, es escasa la evidencia a favor de los emolientes, aunque se ha demostrado que disminuyen la necesidad de esteroides hasta en un 50\%.

Los corticoides tópicos son fundamentales en la fase aguda de la enfermedad. Los primeros días puede utilizarse un corticoide de mediana potencia, pasando posteriormente a uno de baja, como la hidrocortisona al $1 \%$, que es de primera elección en la cara y pliegues. Nunca se aplicaran más de dos veces al día.

Las lociones se usan para las lesiones agudas y exudativas, en zonas pilosas y en cara; mientras que las cremas son utilizadas para las lesiones agudas; y las pomadas y ungüentos en las lesiones liquenificadas.

Cursos cortos de corticosteroides tópicos potentes son equivalentes al uso pro- 
Tabla II. Corticoides tópicos más utilizados por orden de potencia
Baja potencia
- Butirato de clobetasona 0,05\%.
- Acetato de hidrocortisona 1 y $2,5 \%$.
- Aceponato de hidrocortisona 0,125\%.
- Flumetasona 0,25\%.
- Aceponato de metilprednisolona 0,1\%.
Media potencia
Alta potencia
- Acetónido de fluocinolona al 0,025 y
- Acetónido de triamcinolona 0,5\%.
$0,02 \%$.
- Dipropionato de betametasona $0,05 \%$.
- Valerato de betametasona $0,1 \%$.
- Propionato de clobetasol 0,05\%.

longado de corticosteroides de acción leve o suave. Los corticosteroides potentes empleados de manera intermitente, por ejemplo, dos veces a la semana, pueden reducir la frecuencia de las exacerbaciones en comparación a los emolientes.

Los corticoides sistémicos se reservan para los casos muy severos o rebeldes al tratamiento tópico.

\section{Inmunomoduladores tópicos:}

\section{tacrolimus y pimecrolimus}

Ambos macrólidos están indicados para el tratamiento a corto plazo o intermitente a largo plazo de las formas leves, moderadas o graves, cuando estas no respondan adecuadamente o el paciente sea intolerante a la terapia convencional a base de corticoides. Deben administrarse las dosis mínimas necesarias para controlar los síntomas y cesar la administración cuando estos remitan.

Aunque su mecanismo de acción no es del todo bien conocido, parece que ac- túan inhibiendo la calcineurina en la piel, efecto mediante el cual se regula la transcripción de diversos factores implicados en la activación en las fases tempranas de los linfocitos T. Los inmunomoduladores bloquean la activación de las células $\mathrm{T}$; actúan uniéndose a la macrofilina-12, formando un complejo que inhibe a la calcineurina, por lo que se evita la producción de citocinas inflamatorias. La acción selectiva sobre los linfocitos $T$ sin actuar sobre la célula endotelial ni sobre los fibroblastos les confiere la ventaja sobre los corticoides tópicos de no inducir atrofia ni telangiectasias. Cuando el grado de severidad de la enfermedad es importante, el tacrolimus al $0,1 \%$ se muestra más efectivo que el pimecrolimus al $1 \%$ en el alivio de los signos y síntomas de la enfermedad, lo que puede estar en relación con el hecho de que in vitro el tacrolimus tiene una afinidad por la macrofilina tres veces superior al pimecrolimus. La molécula de tacroli- 
mus se aisló en 1984 a partir de Streptomyces tsukubaensis.

Su administración no está recomendada en niños menores de 2 años. Si bien esta es la información recogida actualmente en las fichas técnicas de los citados medicamentos, la Agencia Europea de Medicamentos ha emitido un comunicado con fecha del 22 de enero de 2009 a través del cual adopta una opinión favorable en cuanto a la recomendación de variar los términos recogidos en la autorización de comercialización de las pomadas con tacrolimus. Concretamente, adopta una nueva indicación: el tratamiento de mantenimiento de la DA moderada a severa para la prevención de erupciones y la prolongación de períodos sin erupciones en pacientes que sufren con elevada frecuencia exacerbaciones (cuatro o más al año) y que han tenido una respuesta inicial a un máximo de seis semanas de tratamiento de dos dosis diarias de tacrolimus en pomada (desaparición total o parcial de lesiones).

\section{Tratamiento de la infección}

Se administran antibióticos tópicos 0 sistémicos con actividad antiestafilococo según la gravedad de la infección. Se debe tener en cuenta que muchos casos no evolucionan favorablemente con hidratación y corticoterapia tópica por la presen- cia de infección o colonización por estafilococos. Se postula que las toxinas producidas por $S$. aureus actuarían como súper antígenos, iniciando y perpetuando una respuesta inmunológica anómala.

\section{Tratamiento de los casos especialmente graves}

Se han utilizado otras alternativas, como fototerapia en mayores de 12 años, ciclosporina A, azatioprina, inmunoterapia, IFN-a, inmunoglobulina intravenosa, anti-lgE, etc. La luz ultravioleta ofrece beneficios a corto plazo en casos de DA. Se considera como tratamiento de segunda o tercera línea por sus efectos adversos.
Algoritmo de tratamiento
Sabemos que en el momento actual no existe un tratamiento curativo para la DA, estando los tratamientos actuales centrados en el alivio sintomático de la enfermedad.
De esta forma, en los casos leves o moderados los brotes se controlan en general con el uso de terapia tópica mientras que en los casos graves que no responden al tratamiento tópico es preci- so recurrir a la fototerapia o a los trata- mientos sistémicos (figuras 1 y 2 ).
En el tratamiento inicial, se utilizan emolientes para la xerosis junto a medi- 


\section{Figura 1. Algoritmo de tratamiento.}

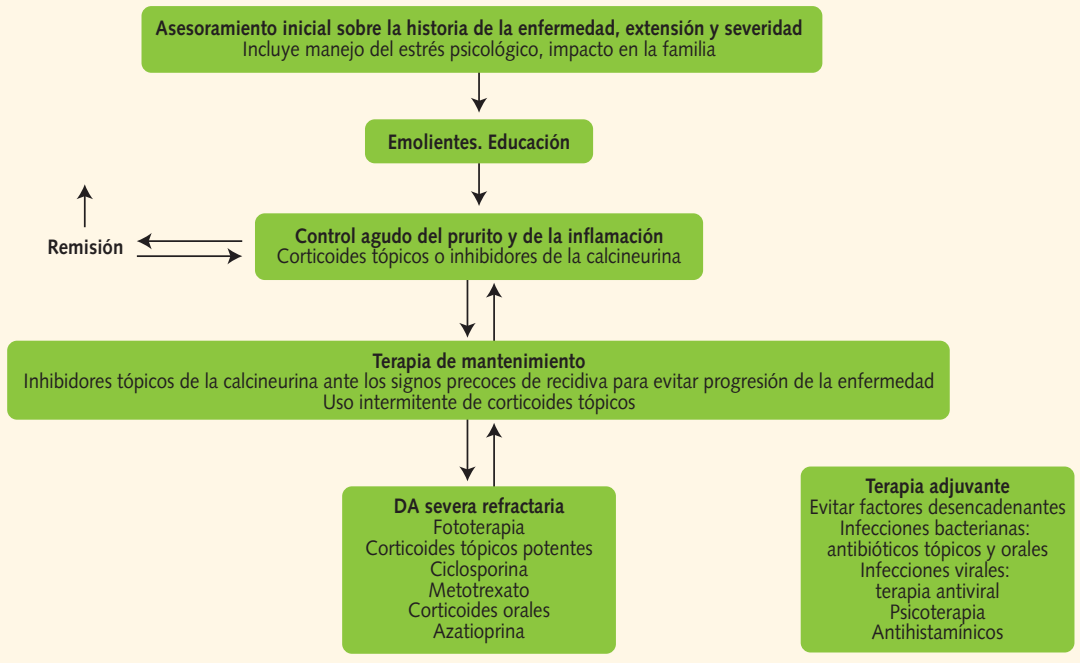

Tomado de: Laguna Argente C, Vilata Corell JJ. Dermatitis atópica del adulto. Med Cutan Iber Lat Am. 2006;34:5-10. Disponible en www.medcutan-ila.org/articulos/2006/1/pdf/05-095.pdf

Figura 2. Algoritmo de tratamiento.

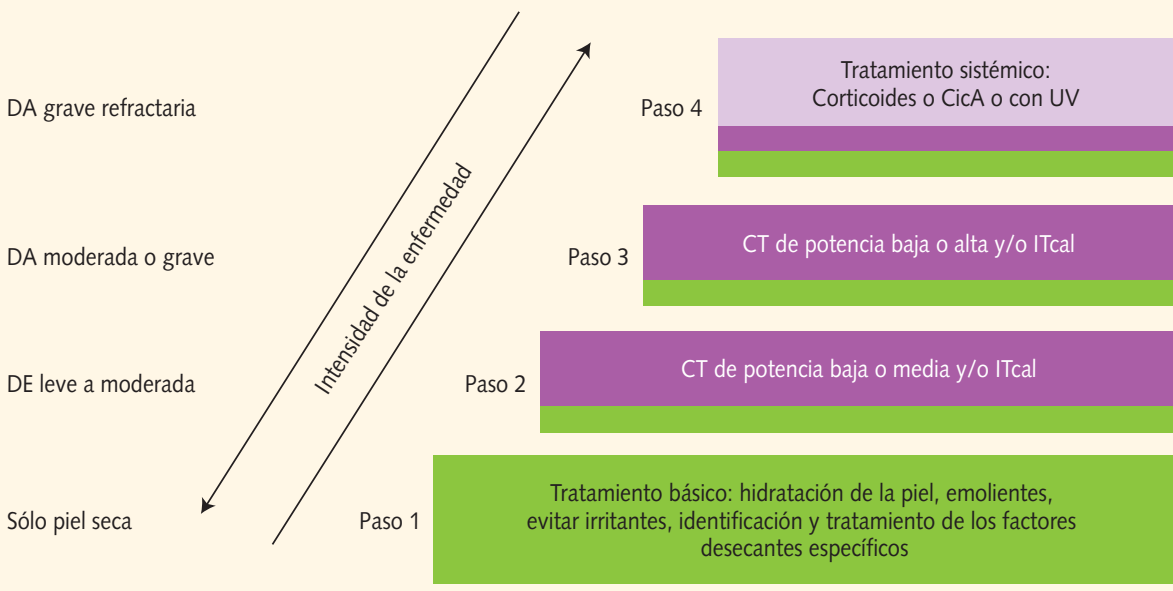

CT: corticoides tópicos; Itcal: inhibidores tópicos de la calcineurina; CicA: ciclosporina A.

Tomado de: Cezmi A. Diagnosis and treatment of atopic dermatitis in children and adults. J Allergy Clin Immunol. 2006;118:152-168. Disponible en www. jacionline.org/article/PIIS0091674906009250/fulltext 
das educativas destinadas a evitar o disminuir la exposición a los factores desencadenantes. En los pacientes que, tras la aparición de las primeras manifestaciones (prurito o eczema), son diagnosticados por primera vez, el tratamiento dependerá de la intensidad de los síntomas. Así, en los casos graves se recomendará el uso durante un corto plazo de tiempo de esteroides tópicos y en los casos moderados-leves, inhibidores tópicos de la calcineurina (ITC) pimecrolimus y tacrolimus.

También se ha demostrado que ambos son muy útiles en el tratamiento a largo plazo. Aplicados al inicio de la sintomatología, son capaces de abortar la aparición de brotes y alargan el espacio entre los mismos, mejorando el control global de la enfermedad y permitiendo reducir o eliminar el uso prolongado de corticoides.

Una vez conseguida la remisión inicial, el paciente deberá continuar con el uso de emolientes. A partir de este momento lo más habitual es que el paciente sufra recurrencias con mayor o menor frecuencia, según los casos. Entonces es cuando la utilización precoz e intermitente de los inhibidores tópicos de la calcineurina adquirirá un especial protagonismo en el control de la enfermedad y logrará la remisión del brote incipiente. Una vez conseguida la remisión se continuará con la aplicación de emolientes. El uso de los corticoides se reservará para las exacerbaciones agudas que no puedan ser controladas con los ITC. Actuando de esta manera se optimiza el papel de los corticoides tópicos, los cuales son muy eficaces en el tratamiento de las exacerbaciones agudas, al mismo tiempo que se minimiza el tiempo durante el cual son utilizados, disminuyendo de esta forma sus potenciales efectos secundarios. Solo en el caso de infecciones graves se debe suspender el tratamiento con los ITC hasta que la infección haya respondido adecuadamente el tratamiento. En caso de infecciones leves y localizadas bastará añadir el tratamiento antiinfeccioso adecuado sin necesidad de suspender el tratamiento, salvo en las zonas de piel infectada. En caso de una erupción variceliforme de Kaposi, se deberán administrar antivirales activos frente al virus del herpes simple por vía sistémica. Si los signos y síntomas de la DA son refractarios al tratamiento tópico se debe recurrir a otras opciones terapéuticas como fototerapia o fármacos de acción sistémica como corticoides orales, ciclosporina, metrotexato, micofenolato mofetil y otros. 